\title{
LOS BUCIOS MUDOS Y LAS ESCULTURAS BISEXUADAS: TRANS-GREDIR EL PASADO PRECOLONIAL CANARIO
}

\section{Daniasa Curbelo}

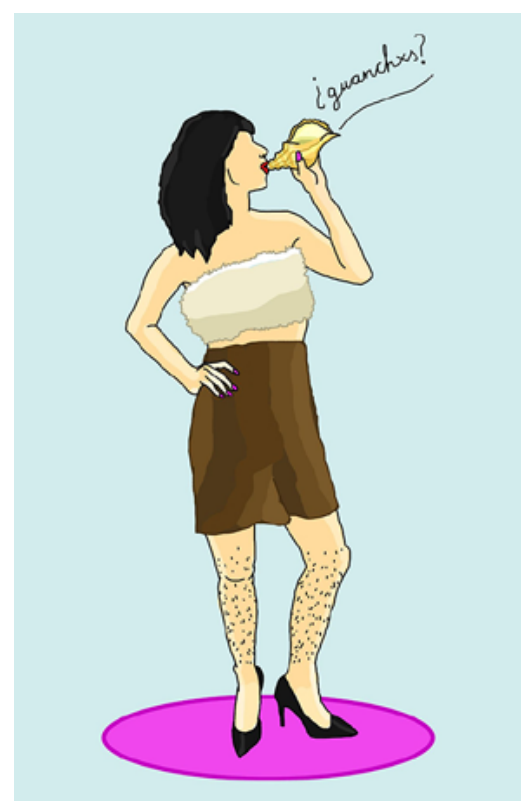

«Guanches, guanchas y... ¿Guanchxs?» Daniasa Curbelo (2019).

El catorce de diciembre de 2019 tuvo lugar el festival Música Arte Creatividad (MÁC) en el Museo de la Naturaleza y la Arqueología de Santa Cruz de Tenerife, institución que expone momias guanches y restos arqueológicos del pasado indígena de las Islas Canarias. Ese día compartí, como parte de la programación, la conferencia performativa "Guanches, guanchas y... ¿Guanchxs?»: una pregunta que, lejos de ser tomada como una broma o un delirio, contiene una gran cantidad de reflexiones y revisiones sobre la sociedad precolonial canaria, las descripciones que hicieron los conquistadores europeos de sus realidades a partir del siglo XV y, por supuesto, la forma en que las instituciones museísticas continúan perpetuando imaginarios que determinan los cuerpos y los géneros por parámetros eurocéntricos y binarios. Una imagen -realizada a partir de las representaciones del italiano 


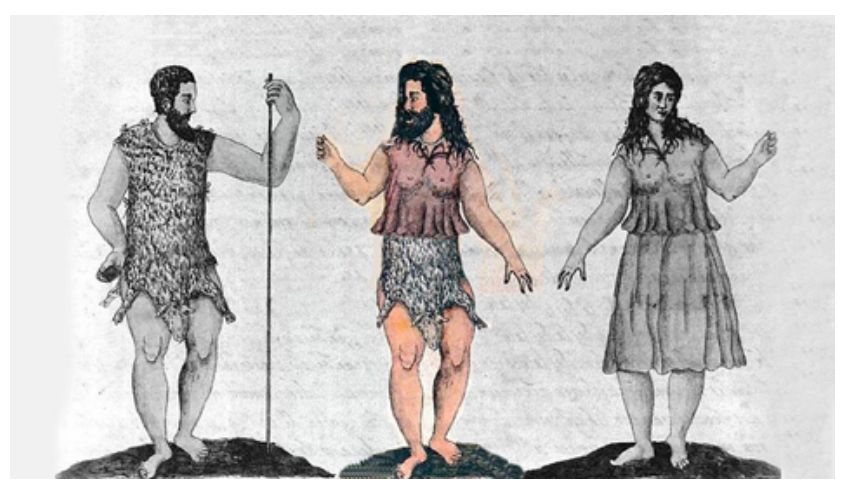

Imagen 1. «Representación trans-gredida de la sociedad aborigen canaria», Daniasa Curbelo (2019).

Leonardo Torriani de una pareja indígena canaria en 1592 y con la que pude generar una tercera identidad a partir de la combinación híbrida de los caracteres considerados como «masculinos» $\mathrm{y}$ «femeninos» (vid. imagen 1) - me acompañó durante toda la ponencia junto a otras imágenes y fragmentos de distintas publicaciones que anteceden a esta conferencia, como son la entrevista "En la tradición amazigh ser homosexual o trans era una bendición divina» o el artículo «Existió la diversidad sexual en Canarias antes de la conquista?», ambos publicados en la página web de la Fundación Canaria Tamaimos.

Una vez finalizada la ponencia me desprendí de un pesado chaquetón negro que portaba para descubrir otra vestimenta: una bufanda blanca a modo de top recordaba una prenda de lana y un pareo de color marrón servía como «falda» de guanche. Subida en mis tacones stiletto y con medias finas, utilicé el pintalabios rojo vino de la marca Essence para pintarme los morros y dibujar sobre mi pecho algunas formas similares a las espirales de los petroglifos canarios. Pedí al público asistente que sacara sus móviles y me fotografiara o grabaran en vídeo porque aquella era la primera, y tal vez última, ocasión en la que «unx guanchx» estaba presente dentro del Museo de Naturaleza y Arqueología de la ciudad, hasta ahora encargado de construir y transmitir un discurso patriarcal, eurocéntrico y binario de la sociedad precolonial canaria. Seguidamente saqué un bucio del bolso e intenté hacerlo sonar con los labios pintados. El «bucio» es una especie de caracol marino de grandes dimensiones que en las Islas Canarias se empleaba antes de la invasión castellana para fabricar un instrumento musical de viento que se sopla desde el extremo y que permite la comunicación entre grandes distancias. La representación clásica y tradicional del uso del bucio en el pasado precolonial canario está innegablemente dominada por sesgo androcéntrico. Este sesgo se ha constituido visualmente en los discursos nacionalistas mediante la figura arquetípica del hombre indígena grande -viril y fuerte-, símbolo de resistencia, fuerza y honor (vid. imágenes 2 y 3 ). Es por este motivo por el que no abundan las imágenes ni representaciones de mujeres 

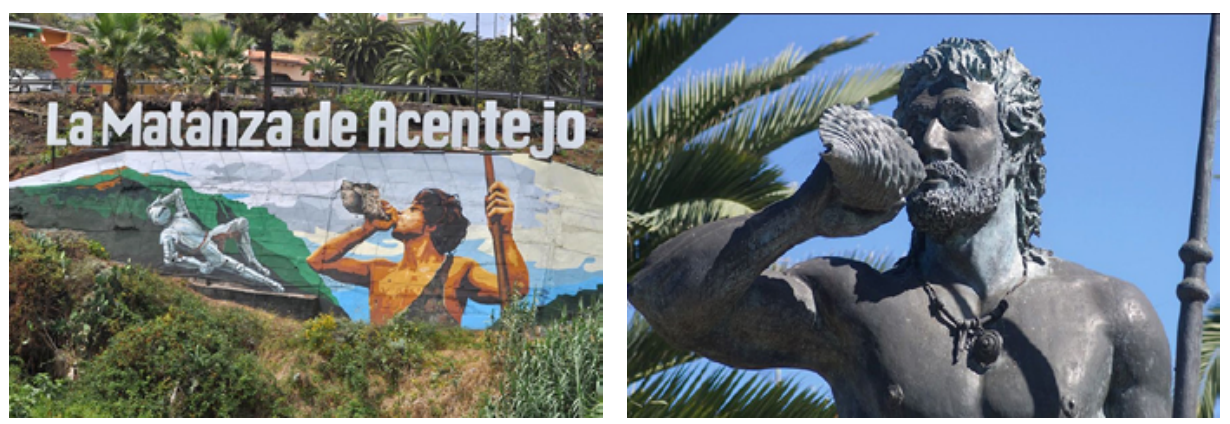

Imágenes 2 y 3. En la primera imagen, fotografía del mural ubicado en el municipio tinerfeño de La Matanza de Acentejo y a su lado la estatua del mismo municipio de Chimenchia (Tinguaro), el guanche que ganó la victoria de Centejo, como ejemplos del androcentrismo imperante que existe en las representaciones indígenas que emplean el bucio.

Imágenes extraídas de redes sociales.

canarias haciendo sonar un bucio, mucho menos otras identidades disidentes del paradigma binario del género ${ }^{1}$.

Durante la performance mi bucio no sonó. No sonó igual que la «X», que es impronunciable. Silenciosa. Sin voz. Lo mismo sucede con el planteamiento de la charla. ¿Cómo hacemos sonar palabras que no pueden ser más que hipótesis y preguntas? ¿Cómo articulamos un planteamiento que cuestione los parámetros binarios y eurocéntricos del relato colonial canario desde dentro de ese mismo discurso hegemónico? Un bucio fallido, una vocal impronunciable y preguntas que se filtran a través de la sólida piedra de instituciones como el Museo de la Naturaleza y la Arqueología, que en el año 2018 modificó su antiguo nombre de «Museo de la Naturaleza y el Hombre» por el actual. Es indiscutible que el museo necesitaba una urgente modificación que superase la concepción de «hombre» como un término universal y representativo de toda la humanidad, de la que también formamos parte las mujeres y otras identidades disidentes. No obstante, al margen de considerar un triunfo esta modificación, el MUNA continúa perpetuando y reproduciendo imaginarios patriarcales y coloniales en sus contenidos. Este hecho es fácilmente perceptible a la hora de buscar la representación de las mujeres más allá del rol de «cuidadoras» en las sociedades precoloniales; o en la incorporación al relato institucional de diferentes extractos de crónicas y textos posteriores a la conquista de

${ }^{1}$ Existe un vídeo publicado en Youtube el seis de marzo del ańo 2016 titulado «Harimaguadas: mujeres sagradas canarias -Música aborigen canaria chamanismo canario- canto chamanico», en el que aparece representada una mujer realizando dicha acción. Más allá de la propuesta musical "chamánica», que recurre a cuencos tibetanos y un dijeridú, esta es una de las pocas excepciones representativas de las que se tiene constancia de canarias haciendo sonar un bucio. 

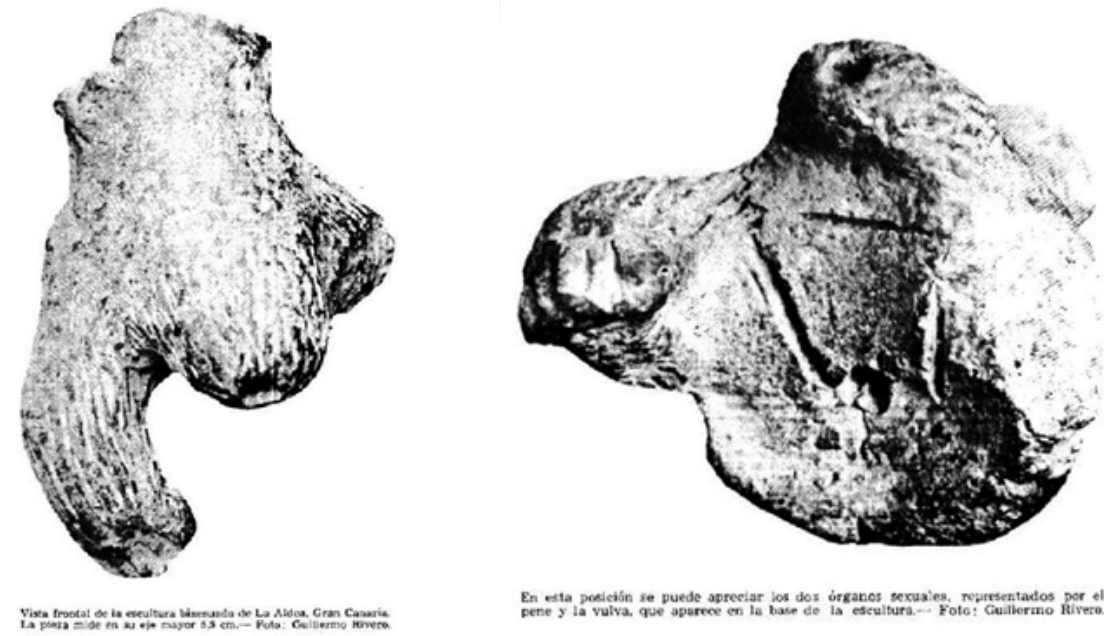

En esta poeicín se puede apreeiar los dos írganos sexusies. Norresentados por el

Imágenes 4 y 5 . Fotografías extraídas del artículo «Una escultura bisexuada procedente de la Aldea de San Nicolás (Gran Canaria)», de Julio Cuenca y José de León (1983).

las Islas que definen a sus indígenas desde imaginarios coloniales y eurocéntricos, como es por ejemplo el uso del concepto de «buen salvaje» de Jean-Jacques Rousseau en textos expositivos. El MUNA se añadiría así a una larga lista de museos de Historia, Naturaleza y Arqueología ubicados en Canarias y otros territorios con un pasado y presente similares al del Archipiélago, que requieren una profunda reconfiguración de la narración expuesta.

Los arqueólogos Julio Cuenca Sanabria y José de León (1983), en su estudio «Una escultura bisexuada procedente de la Aldea de San Nicolás (Gran Canaria)», publicada por el Museo Canario, señalan que la agrupación de restos arqueológicos dispersos por Gran Canaria ha permitido impulsar el conocimiento sobre la cultura sexual de la sociedad precolonial isleña. La escultura «bisexuada», que así la definen los arqueólogos, fue descubierta en la finca de Tirma, la cual forma parte del entorno donde se sostiene la existencia de restos arqueológicos sagrados en la cosmovisión indígena (vid. imágenes 4 y 5). La figurilla estudiada por Cuenca y De León es de barro cocido, mide cinco centímetros y medio de altura y su peso es de apenas treinta y siete gramos. Prácticamente le falta toda la parte correspondiente a la cabeza y extremidades superiores, aunque conserva una parte del tronco, así como la extremidad inferior derecha y el arranque de la extremidad izquierda; entre ambas sobresale lo que se interpreta como un pene erecto, exageradamente representado en relación con las extremidades. Los estudiosos señalan que «lo que realmente confiere a esta escultura un carácter excepcional es el hecho de tener claramente señalados ambos sexos» porque el «órgano sexual masculino» está «representado de forma algo exagerada, sobresaliendo entre las extremidades inferiores, y el órgano femenino, 


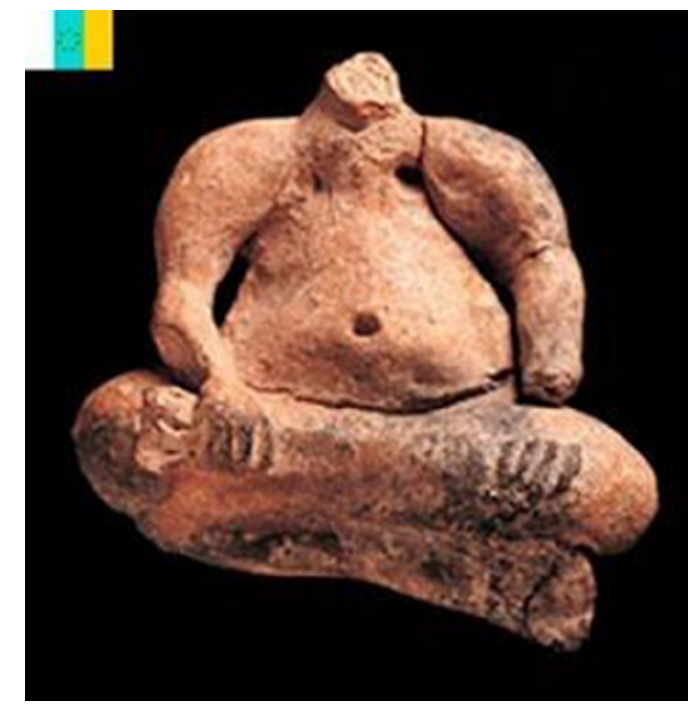

Imagen 6. Ídolo de Jinámar -yacimiento de Los Barros-. Imagen extraída de redes sociales.

que se representa de forma esquematizada por medio de incisiones que forman una figura triangular equilátera en la base de la escultura. Se trata de la figuración de un ser bisexual o hermafrodita» (Cuenca y De León: 102-105).

Otro trabajo que podemos poner en relación con la interpretación de esta escultura es el que se publicó en "Las manifestaciones artísticas prehispánicas y su huella». Sus autores, Antonio Tejera Gaspar, José Juan Jiménez González y Jonathan Allen (2008), dedicaron varias páginas a las representaciones de la figura humana al completo o de sus partes más significativas, entre las que se encuentran los atributos sexuales, y establecieron varios subgrupos (antropomorfos femeninos, masculinos, bisexuados y asexuados) como intento de clasificación formal, haciendo referencia a unas pocas piezas por su carácter singular (Tejera, Jiménez y Allen: 125). En el apartado dedicado a los «antropomorfos bisexuados» aparece la estatuilla mencionada anteriormente junto al «Ídolo de Chil», de veintiséis centímetros de altura, el cual constituye una escultura «sedente con los pies cruzados y los brazos curvados [...] la cabeza es pequeña en proporción al cuerpo [...] y los miembros inferiores y superiores aparecen abultados con formas esteatopígicas. Según C. Martín de Guzmán, podría tratarse de un andrógino que se ha representado con rasgos femeninos y al que se le ha añadido un pene entre las piernas» (127). Los investigadores también mencionan al «Ídolo de Los Barros» (vid. imagen 6), una figura con «apariencia masculina que en el torso tiene dos rehundimientos que cabría relacionar con unos pechos artificiales, de los que sólo quedarían las improntas al desaparecer el relleno» (ibid.). 
Estos yacimientos arqueológicos canarios, enfocados desde las teorías decoloniales, podrían revisarse como representaciones de la cosmovisión del género precolonial en el Archipiélago, al igual que sucede en otros territorios colonizados, en tanto que «son contenedores bastante detallados de aspectos físicos (partes del cuerpo) y culturales (tratamiento de partes del cuerpo, así como vestimenta y parafernalia) que sin duda están atravesados por los conceptos de género manejados por la sociedad que los fabricó» (Ugalde: 112).

Diferentes estudios sobre iconografías precolombinas en Ecuador, como es el caso del trabajo de María Fernanda Ugalde (2017) o de Felipe Armstrong (2019), han incorporado una perspectiva de género o metodologías basadas en la teoría queer/cuir. De este modo se han revisado muchas estatuillas y representaciones antropomorfas desde visiones no binarias ni heteronormativas, en busca de hacer mayor justicia al simbolismo expresado por las poblaciones antiguas hace algunos siglos o incluso milenios (Ugalde: 108). El análisis que nos presenta la antropóloga sobre las figurillas antropomorfas de la costa ecuatoriana cuestiona y dinamita los parámetros normativos y eurocéntricos con los que se han intentado explicar dichas representaciones, puesto "que ocasionalmente aparecen personajes que combinan atributos físicos propios de un sexo con vestimentas clásicas para el otro sexo" (109); a este respecto, habría que añadir que en la cultura tolita la diferenciación entre masculino y femenino se ha establecido en función del vestido que lleva la estatuilla, asociado también a rasgos físicos que serían indicadores del sexo fenotípico, y «que nos dejó la duda también sobre la posible existencia de al menos un tercer género, lo cual nos alentó a profundizar en la indagación de la representación del género en las iconografías antiguas de la costa ecuatoriana» (idem). Otra de las representaciones antropomorfas más frecuentes de las culturas de la costa ecuatoriana, especialmente en Tolita y Bahía, son las parejas o grupos de personas, que se han interpretado como escenas familiares en clave de «matrimonios», "parejas» o «escenas eróticas» cuando la pareja se divide en un personaje «masculino» y otro «femenino». Sin embargo, cuando hablamos de figuras en las que los dos personajes pueden ser identificados como individuos de «sexo femenino», la interpretación varía de "matrimonio» o "pareja» para ser consideradas como «siamesas» (vid. imagen 7), pues «mayoritariamente este tipo de figuras no han sido expuestas ni tematizadas, tal vez por considerarse poco representativas, tal vez por evadir la necesidad de profundizar en la posibilidad de la homosexualidad como práctica socialmente admitida en el pasado" (Ugalde: 110), tal y como evidencian las primeras crónicas de la conquista de Abya Yala (nombrada "América» por los conquistadores), en las que, en palabras de Michael Horswell, «era muy usual la manifestación de la preferencia sexual entre personas del mismo sexo, que se practicaba libre y abiertamente, sin sanción social alguna, para horror de los observadores españoles, que la tachaban de pecado nefando» (apud Ugalde: 111).

Por su parte, Felipe Armstrong se encarga de cuestionar las categorías empleadas para el estudio de estatuillas de madera producidas por la sociedad Rapa Nui, originaria de la Isla de Pascua, antes e inmediatamente después de la invasión europea a comienzos de 1722, "con el fin de visibilizar un conjunto de objetos que no cumplen con los estándares normativos de dichas categorías [...] [y visibilizar una] 

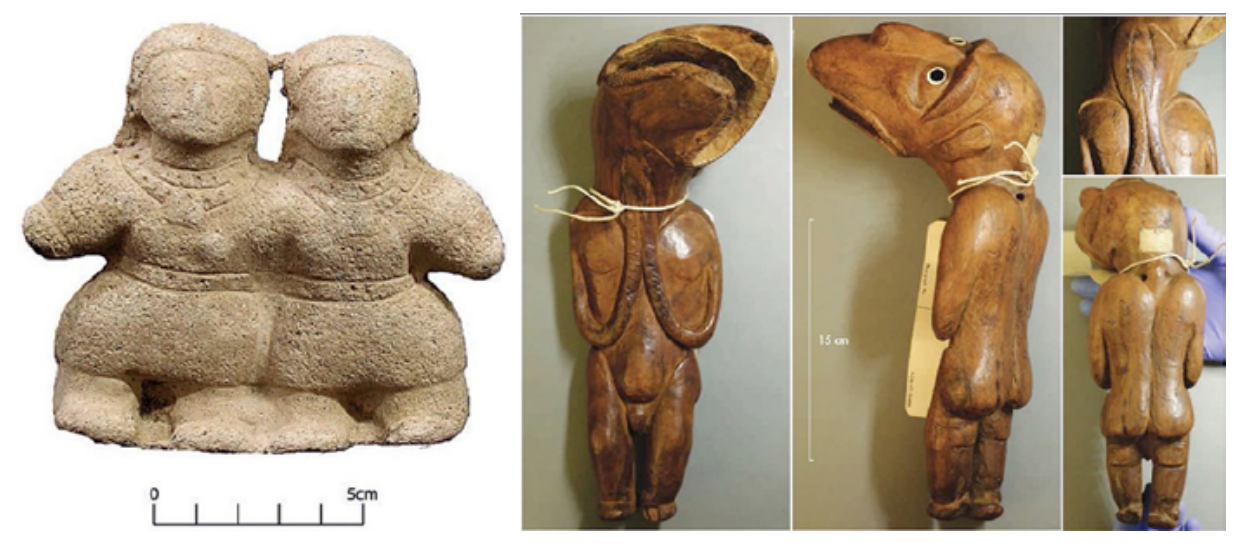

Imagen 7. Figuras Tumaco-Tolita. Museo de Antropología y Arte Contemporáneo (MAAC) Guayaquil, Ecuador. GA-43-2015-8. Vista en Ugalde, 2009: 112.

Imagen 8. Diferentes vistas de una estatuilla con cualidades humanas y reptiles.

British Museum 8700. Fotografías del Felipe Armstrong, visto en Armstrong, 2019: 99.

fluidez de cualidades que hace difícil la aplicación de modelos cartesianos rígidos sobre el cuerpo y los objetos, a la vez que apuntan a un mundo construido sobre la combinación de atributos y cualidades» (Armstrong: 89). Las manifestaciones antropozoomorfas creadas por la sociedad Rapa Nui se han dividido tradicionalmente en cinco categorías en función de sus características y particularidades; no obstante, el autor nos hace ver que dicha clasificación no es capaz de abarcar toda la diversidad de estatuillas de madera que existen y que se han tachado de "arte aberrante», lo que nos «recuerda conceptos como 'desviado', 'anormal', 'inapropiado', etc., asumiendo de manera implícita, pero evidente, la existencia de lo 'normal'; en este caso, una forma normal de ser cuerpo de madera" (96). Todo esto evidencia una forma de clasificación arqueológica basada en la relación binaria de normalidad/otredad, una visión también presente en la estructura representacional del género y la sexualidad en Occidente. Un análisis de 372 estatuillas de maderas con rasgos humanos y de otras especies animales, atributos cadavéricos, partes del cuerpo duplicadas, genitales en distintas formas o su ausencia y otros elementos, combinados para originar cuerpos únicos y superar los límites figurativos entre especies y sexos, pone de manifiesto «la variedad de atributos iconográficos y, por tanto, la diversidad de cuerpos de madera [cuyas] combinaciones ofrecen una red multidimensional en la que los objetos se ubican de acuerdo a sus cualidades» (97). Las estatuillas, imposibles de clasificar a partir de una de las cinco categorías convencionales sino ubicadas entre dos o más de estas, nos ofrecen un amplio abanico de posibilidades corporales que desafía las fronteras entre humanos y no humanos (vid. imagen 8) y "es probable que jugaran un rol en la autopercepción de los humanos, afirmando la posibilidad de transformación e incorporación de diversas cualidades» (100), tal y como podría ser el caso que nos menciona el autor del ritual Rapa Nui del hombre-pájaro, por el 


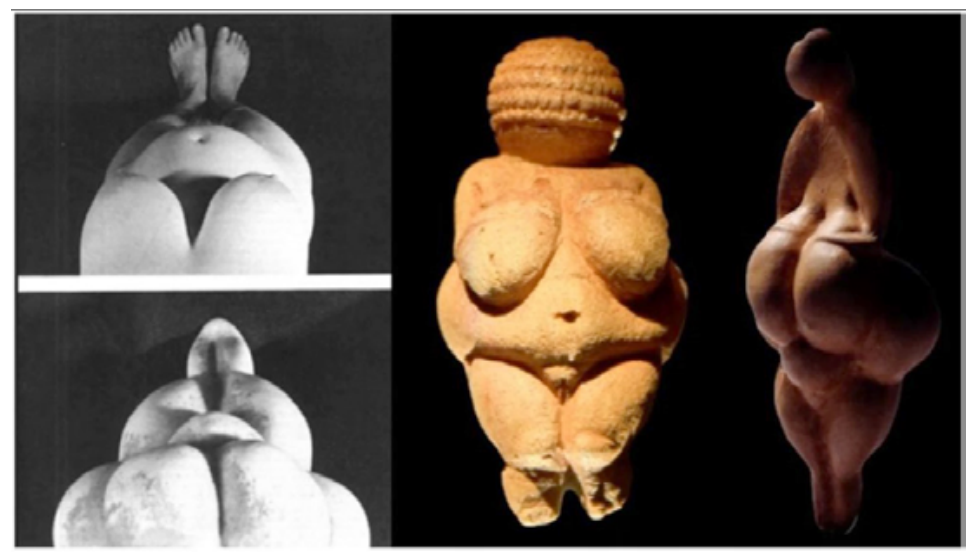

Imagen 9. Comparación entre las figuras, entre las que está la Venus de Willendorf, con fotografías de una mujer moderna embarazada extraídas del trabajo de McDermott y McCoid (1996).

que un vencedor de la competición adquiría una suerte de nueva identidad híbrida que le otorgaba cualidades y beneficios sociales durante el transcurso de un año.

A partir de lo que se ha expuesto, la arqueología puede definirse como una interpretación situada de restos que nos quedan del pasado, de modo que «las formas en las que la arqueología ha clasificado sus objetos de estudio y definido los fenómenos sociales se encuentran enraizadas e influenciadas por las formas hegemónicas contemporáneas de relacionarse con el mundo y sus diferentes elementos» (Armstrong: 90). Otro claro ejemplo de este fenómeno de interpretación sesgada se cristaliza en las llamadas "Venus del Paleolítico» y las recientes resignificaciones que se han propuesto sobre su concepción. En contra de la creencia académica tradicional que las definió como un «ideal de belleza prehistórico» constituido a partir de la mirada masculina, estas pequeñas y milenarias estatuillas descubiertas a finales del siglo xIX podrían ser radicalmente reconfiguradas desde otra perspectiva no androcéntrica. Sus atributos exagerados (la prominencia del vientre, torso anormalmente delgado, pechos grandes y colgantes, nalgas y muslos voluminosos, piernas cortas, pies pequeños y ausencia de rostro o cabeza agachada) han servido como evidencia para autoras como Leroy McDermott y Catherine Hodge McCoid (1996) de que «estas aparentes distorsiones de la anatomía se convierten en representaciones adecuadas si consideramos el cuerpo visto por una mujer que se mira a sí misma» (McCoy y McDermott: 320) (vid. imagen 9). Esto nos revelaría que los estudios antropológicos de la época asumieron que las mujeres de la prehistoria mantenían una actitud pasiva y eran los hombres quienes realizaron representaciones de sus cuerpos, ya sea por sus atributos sexuales o como símbolos de fecundidad, lo cual no puede estar más cuestionado.

Entonces, ¿por qué no podemos plantear posibilidades que se escapen del binarismo de género en la sociedad precolonial del archipiélago canario? Pese a que 
«la arqueología lleva ya algunas décadas preocupándose por el tema del género en la Prehistoria y ha hecho el esfuerzo de procurar una aproximación a los roles de género en el pasado que partía en los años ' 80 de una crítica feminista al carácter históricamente androcentrista de la disciplina [...] y tomando en cuenta la gran variedad de estudios que procuran un acercamiento a la diversidad y posible fluidez sexual en el pasado (gender fluidity) con los que hoy contamos en arqueología a nivel global, llama la atención que pocos de ellos se hayan fijado en la iconografía como fuente válida de información» (Ugalde: 111-112), lo cual nos continúa situando en un estado de desamparo ante las rígidas concepciones hegemónicas que definen y explican los pasados precoloniales de territorios como Ecuador, Rapa Nui y Canarias. Fuentes como la etnografía, la filosofía, los estudios de género, los estudios decoloniales y la Teoría Queer han regado y fertilizado el desarrollo de nuevos paradigmas en la disciplina arqueológica, ofreciendo nuevas formas de acercarse a las representaciones antropomorfas que a su vez cuestionen aquellas categorías rígidas e inmutables que el discurso hegemónico colonial establece como "verdaderas» $\mathrm{y}$ "de esta manera, des-categorizando estos objetos es posible comenzar a visualizar nuevas formas de entendimiento» (Armstrong: 99).

No obstante, quisiera recordar que para esta cuestión anterior no podemos plantear certezas de ningún tipo, solo hipótesis. Preguntas que amplíen los horizontes y que cuestionen el sistema representacional que articula el imaginario precolonial canario, ubicado en un marco tan reducido por parámetros binarios y heteronormativos. Como diría la feminista hindú Gayatri Spivak, solo podemos hacer "presente" al sujeto subalterno y marginalizado señalando su ausencia en el discurso hegemónico. El bucio seguirá «mudo» con su incómodo silencio retumbando en las delgadas grietas del relato establecido. 


\section{BIBLIOGRAFÍA Y WEBGRAFÍA CONSULTADA}

Armstrong, Felipe. (2019). «Cuerpos de madera. Diversidad y relacionalidad en objetos antropo/ zoomorfos de Rapa Nui obtenidos entre los siglos xviII y xx». Boletín del Museo Chileno de Arte Precolombino, 24:2, pp. 89-105 (https://scielo.conicyt.cl/pdf/bmchap/v24n2/07186894-bmchap-24-02-00089.pdf).

Cuenca Sanabria, Julio y De León Hernández, José. (1983) «Una escultura bisexuada procedente de la Aldea de San Nicolás (Gran Canaria)». El Museo Canario, 43, pp. 101-109 (https:// dialnet.unirioja.es/servlet/articulo?codigo=2537287).

McCoid, Catherine H. y McDermott, Leroy D. (1996) «Toward Decolonizing Gender. Female Vision in the Upper Paleolithic». American Anthropologist, New Series, 98:2 June, pp. 319326. (https://mymission.lamission.edu/userdata/schustm/docs/VenusFigurines-WomensPerspective_HIGHLIGHTED.pdf).

UGAlde, María Fernanda. (2017) «De siamesas y matrimonios: tras la simbología del género y la identidad sexual en la iconografía de las culturas precolombinas de la costa ecuatoriana», en Gutiérrez Usillos, Andrés (coord.), Trans* Diversidad de identidades y roles de género, catálogo de la exposición (Madrid, 22 junio-24 septiembre 2017). Museo de América, pp. 108-118. (http://chrysallis.org.es/wp-content/uploads/2015/11/Cat\%C3\%A1logo-Museo-de-Am\%C3\%A9rica.pdf).

Tejera Gaspar, Antonio, Jiménez González, José Juan y Allen, Jonathan (2008). Las manifestaciones artísticas prehispánicas y su huella. Historia Cultural del Arte en Canarias. Tomo I. Gobierno de Canarias (https://mdc.ulpgc.es/cdm/ref/collection/MDC/id/163389). 